\title{
Steroid receptor coactivator-3 glutamine repeat polymorphism and the androgen insensitivity syndrome
}

\author{
Nigel P Mongan, Jarmo Jääskeläinen, Sumit Bhattacharyya ${ }^{1}$, Roberta M Leu and Ieuan A Hughes \\ University Department of Pediatrics and ${ }^{1}$ Department of Medicine, Addenbrooke's Hospital, University of Cambridge, Cambridge CB2 2QQ, UK
}

(Correspondence should be addressed to N P Mongan, Department of Pharmacology, Weill Medical College of Cornell University, 1300 York Avenue, New York 10021, USA; Email: n.p.e.mongan.95@cantab.net)

Defects in androgen signaling can result in complete and partial male undermasculinization (1). The androgen receptor (AR) mediates the actions of the androgens testosterone and $5 \alpha$-dihydrotestosterone in male embryonic and pubertal development. The AR is a member of the nuclear receptor superfamily of liganddependent transcription factors (2). The AR includes a polymorphic region of $11-31$ glutamine repeats (AR[Gln]n). Longer AR[Gln]n tracts are associated with both partial androgen insensitivity (PAIS) in XY males (3) and the rare X-linked spinal and bulbar muscular atropy (SBMA) (4) which is often associated with infertility, testicular atropy and gynecomastia. The recruitment of multiple coactivator proteins is required for optimal AR function (5). It was demonstrated recently that the AR[Gln]n expansion found in SBMA diminishes interactions of the ARA-24 coactivator with the AR, resulting in decreased androgendependent transactivation (6). Similarly, it would be expected that coactivator mutations or polymorphisms which interfere with receptor-coactivator interactions would likely result in decreases in androgen-dependent transactivation. Although some cases of complete and partial androgen insensitivity are caused by mutations within the AR or defects in androgen synthesis, for most cases there is no identifiable defect in androgen production and no AR mutation (7). In these cases it is necessary to investigate other coactivator proteins that interact with the AR and are required for optimal AR function.

There is compelling genetic and clinical evidence suggesting that impaired coactivator function may result in partial hormone resistance syndromes. Mouse genetic models reveal that disruption of the steroid receptor coactivator $(\operatorname{SRC})-1(8,9)$ and SRC-3 (p/CIP/RAC3/AIB1/ACTR/TRAM-1) (10) can result in multiple nuclear hormone resistance syndromes. Furthermore, recent clinical reports also suggest a possible coactivator basis for hormone resistance syndromes $(11,12)$. SRC-3 is an AR coactivator (13) which contains a polymorphic glutamine repeat, SRC-3[Gln]n, encoded by a variable track of CAG/CAA codons in $S R C-3$ (14). Although the functional consequences of differences in SRC-3[Gln]n lengths have yet to be studied, the relationships between this polymorphism and breast $(15,16)$ and prostate $(17,18)$ cancer risks have been investigated.

In this study we investigated whether variation in the SRC-3[Gln]n may contribute to the etiology of male undermasculinization. A heterogeneous group of undermasculinized patients $(n=65)$ with normal AR binding attributes, wild type AR sequence determined by single strand conformational polymorphism (SSCP) and/or sequence screening (7), and with AR[GIn]n within the normal range were selected from the Cambridge Intersex Database (1). Local ethics committee approval was obtained for the use of patient samples as part of a sexual development disorders research program. To avoid selection bias for ethnicity or geography, control subjects $(n=57)$ were selected from the same database. The control subjects harbored either an AR mutation or a diagnosis of Denys-Drash syndrome. These subjects have been shown to have the same AR[Gln]n profile as found in the normal population (3). Failure to detect a difference between allele distributions in the control and test cohorts would favor the null hypothesis of no contribution between SRC-3[Gln]n variants and undermasculinization. The unpaired $t$-test was used to compare mean SRC$3[\mathrm{Gln}] \mathrm{n}$ length between groups. Statistical significance was regarded as $P \leq 0.05$.

Two rounds of polymerase chain reaction (PCR) were used to amplify the polyglutamine encoding region of the $S R C-3$ gene. The first round used primer sequences, $5^{\prime}$ - cag agc cga cag gca ctt gaa ttg-3' (forward) and 5'- gac tga tag atg gat gca gcc tgc $g$-3' (reverse). The second, nested, round of PCR used primer sequences, $5^{\prime}$-tcc gac aac aga ggg tgg cta $\mathrm{tg}$-3' (forward), and 5'-tta gga ggt ggg ctg aag gcc $\mathrm{tg}^{-3^{\prime}}$ (reverse), using protocols described previously (14). The reverse primer was labeled with FAM for patients and HEX for control DNA amplifications. Thermal cycling was performed as follows: $95^{\circ} \mathrm{C}$ for $5 \mathrm{~min}$, followed by 35 cycles of $94{ }^{\circ} \mathrm{C}$ for $30 \mathrm{~s}, 56^{\circ} \mathrm{C}$ for $30 \mathrm{~s}$ (oligonucleotide annealing), $72{ }^{\circ} \mathrm{C}$ for $90 \mathrm{~s}$ (DNA synthesis). The PCR products were mixed with GS-350-TAMRA size standard markers (Applied BioSystems, Warrington, UK) and loading buffer, and were heat denatured and electrophoresed on an ABI 377 sequencer. Several samples were electrophoresed on multiple gels to control for discrepancies 
between each run. The band sizes were analyzed using Genescan software (Applied Biosystems).

The distributions of SRC-3 CAG/CAA alleles and genotype repeat lengths by case-control status are shown in Table 1. Among controls, the CAG/CAA repeat length ranged from 26 to 30 (mean: 29.23, $n=114$ alleles). For both undermasculinized and control subjects, the most common alleles contained 28, 29 and 30 repeats (Table 1). Amongst undermasculinized males, CAG/CAA length ranged from 25 to 32 repeats (mean $=28.58, n=130$ alleles). The most common genotypes in the undermasculinized group were 28/29 (16.9\%), 29/30 (23.1\%) and 30/30 (10.8\%). In the control group the most common genotypes were $27 / 30$ (10.5\%), 29/30 (63.2) and 30/30 $(10.5 \%)$. These data contrast with previous reports that 28/29 and 29/29 were the most common genotypes in breast $(16)$ and prostate $(17,18)$ cancer patients. This may reflect a true difference with the UK population or population bias within the Cambridge Intersex Database. However, when the mean SRC$3[\mathrm{Gln}] \mathrm{n}$ length was compared between undermasculinized males and controls using an unpaired $t$-test, the mean SRC-3[Gln]n number was significantly shorter in undermasculinized males (mean: 28.58, $n=130$

Table $1 S R C$-3 CAG/CAA allele and genotype distribution in undermasculinized male patients and controls.

\begin{tabular}{|c|c|c|}
\hline$S R C-3$ allele & Patients (\%) & Controls (\%) \\
\hline 25 & $3(2.3)$ & $0(0)$ \\
\hline 26 & $12(9.2)$ & $2(1.8)$ \\
\hline 27 & $12(9.2)$ & $11(9.6)$ \\
\hline 28 & $26(20)$ & 2 (1.8) \\
\hline 29 & $34(26.2)$ & $43(37.7)$ \\
\hline 30 & $40(30.8)$ & $56(49.1)$ \\
\hline 31 & $2(1.5)$ & $0(0)$ \\
\hline 32 & $1(0.77)$ & $0(0)$ \\
\hline Total & 130 & 114 \\
\hline \multicolumn{3}{|l|}{ Genotype } \\
\hline $25 / 26$ & $3(4.6)$ & $0(0)$ \\
\hline $26 / 27$ & $1(1.5)$ & $1(1.8)$ \\
\hline $26 / 28$ & $3(4.6)$ & $0(0)$ \\
\hline $26 / 29$ & $3(4.6)$ & $0(0)$ \\
\hline $26 / 30$ & $2(3.1)$ & $1(1.8)$ \\
\hline $27 / 28$ & $4(6.1)$ & $0(0)$ \\
\hline $27 / 29$ & $3(4.6)$ & $4(7.0)$ \\
\hline $27 / 30$ & $4(6.1)$ & $6(10.5)$ \\
\hline $28 / 28$ & $2(3.1)$ & $0(0)$ \\
\hline $28 / 29$ & 11 (16.9) & $1(1.8)$ \\
\hline $28 / 30$ & $3(4.6)$ & $1(1.8)$ \\
\hline $28 / 32$ & $1(1.5)$ & $0(0)$ \\
\hline $29 / 29$ & $1(1.5)$ & $1(1.8)$ \\
\hline $29 / 30$ & $15(23.1)$ & $36(63.2)$ \\
\hline $30 / 30$ & $7(10.8)$ & $6(10.5)$ \\
\hline $30 / 31$ & $2(3.1)$ & $0(0)$ \\
\hline Total & [65] & [57] \\
\hline
\end{tabular}

Mean SRC-3[GIn]n number was shorter in undermasculinized patients (mean: 28.58, range: $25-32, n=130)$ than in control males $(29.23$, range: 26-30, $n=114, P=0.0003$ ). alleles) than in the control group (mean: 29.23, $n=$ 114 alleles, $P=0.0003)$.

The p160 coactivators, including SRC-3, contain intrinsic histone acetyltransferase (HAT) activity and are known to interact with nuclear receptors via several well-characterized LxxLL motifs, where L is leucine and $\mathrm{x}$ is any amino acid, and act to recruit additional HAT proteins to the promoter-receptor complex (5). Although the exact pathogenic mechanism of polyglutamine polymorphisms in human disorders remains controversial (19), there is increasing evidence that decreases in HAT activity may be an important cause of the cellular pathogenesis (20). Although it was surprising to find that mean SRC-3[Gln]n lengths were shorter in undermasculinized males relative to controls, further experimental studies are needed to define the functional consequences of variability in SRC-3[Gln]n lengths. It is possible that shorter SRC-3[Gln]n repeat lengths may subtly modulate or destabilize coactivator-receptor interactions, resulting in impairment of androgen-dependent transactivation, and thereby contribute to the etiology of genital abnormalities. Future clinical studies may wish to examine the SRC-3[Gln]n polymorphism in other phenotypes related to decreases in AR function, including testes maldescent and hypospadias, particularly when the functional consequences of the observed variability in SRC-3[Gln]n lengths is understood.

\section{Acknowledgements}

The authors thank all the clinicians who sent samples and details to the Cambridge Intersex Database. This research was supported by the Birth Defects Foundation (N P M), an ESPE Research Fellowship sponsored by Novo Nordisk A/S (J J), an Endocrine Society Summer Fellowship (R M L), and the EU BioMed Program. The authors are extremely grateful to Dr Han N Lim (MIT, USA) for advice and comments on the manuscript.

\section{References}

1 Ahmed SF, Cheng A, Dovey L, Hawkins JR, Martin H, Rowland J et al. Phenotypic features, androgen receptor binding, and mutational analysis in 278 clinical cases reported as androgen insensitivity syndrome. Journal of Clinical Endocrinology and Metabolism $2000 \mathbf{8 5}$ 658-665.

2 Brinkmann AO, Blok LJ, de Ruiter PE, Doesburg P, Steketee K, Berrevoets CA et al. Mechanisms of androgen receptor activation and function. Journal of Steroid Biochemistry and Molecular Biology $199969307-313$.

3 Lim HN, Chen H, McBride S, Dunning AM, Nixon RM, Hughes IA et al. Longer polyglutamine tracts in the androgen receptor are associated with moderate to severe undermasculinized genitalia in XY males. Human Molecular Genetics 20009 829-834.

4 La Spada AR, Wilson EM, Lubahn DB, Harding AE \& Fischbeck $\mathrm{KH}$. Androgen receptor gene mutations in X-linked spinal and bulbar muscular atrophy. Nature 1991352 77-79.

5 Heinlein CA \& Chang C. Androgen receptor (AR) coregulators: an overview. Endocrine Reviews 200223 175-200. 
6 Hsiao PW, Lin DL, Nakao R \& Chang C. The linkage of the Kennedy's Neuron Disease to ARA-24, the first identified androgen receptor polyglutamine region-associated coactivator. Journal of Biological Chemistry $199927420229-20234$.

7 Batch JA, Williams DM, Davies HR, Brown BD, Evans BA, Hughes IA et al. Androgen receptor gene mutations identified by SSCP in fourteen subjects with androgen insensitivity syndrome. Human Molecular Genetics 19921 497-503.

8 Xu JM, Qiu YH, DeMayo FJ, Tsai SY, Tsai MJ \& O’Malley BW. Partial hormone resistance in mice with disruption of the steroid receptor coactivator-1 (SRC-1) gene. Science $1998 \quad 279$ $1922-1925$.

9 Weiss RE, Xu JM, Ning G, Pohlenz J, O'Malley BW \& Refetoff S. Mice deficient in the steroid receptor co-activator 1 (SRC-1) are resistant to thyroid hormone. EMBO Journal 199918 1900-1904.

$10 \mathrm{Xu}$ J, Liao L, Ning G, Yoshida-Komiya H, Deng C \& O'Malley BW. The steroid receptor coactivator SRC-3 (p/CIP/RAC3/AIB1/ ACTR/TRAM-1) is required for normal growth, puberty, female reproductive function, and mammary gland development. PNAS $2000976379-6384$.

11 New MI, Nimkarn S, Brandon DD, Cunningham-Rundel S, Wilson RC, Newfield RS, Vandermeulen J, Barron N, Russo C, Loriaux DL \& O'Malley B. Resistance to several steroids in two sisters. Journal of Clinical Endocrinology and Metabolism 1999 84 4454-4464.

12 Adachi M, Takayanagi R, Tomura A, Imasaki K, Kato S, Goto K et al. Androgen-insensitivity syndrome as a possible coactivator disease. New England Journal of Medicine 2000343 856-862.

13 Tan JA, Hall SH, Petrusz P \& French FS. Thyroid receptor activator molecule, TRAM-1, is an androgen receptor coactivator. Endocrinology $20001413440-3450$.
14 Hayashi Y, Yamamoto M, Ohmori S, Kikumori T, Imai T, Funahashi $\mathrm{H}$ et al. Polymorphism of homopolymeric glutamines in coactivators for nuclear hormone receptors. Endocrine Journal $199946279-284$.

15 Shibata A, Hayashi Y, Imai T, Funahashi H, Nakao A \& Seo H. Somatic gene alteration of AIB1 gene in patients with breast cancer. Endocrine Journal 200148 199-204.

16 Rebbeck TR, Wang Y, Kantoff PW, Krithivas K, Neuhausen SL, Godwin AK et al. Modification of BRCA1- and BRCA2-associated breast cancer risk by AIB1 genotype and reproductive history. Cancer Research $2001615420-5424$.

17 Platz EA, Giovanucci E, Brown M, Cieluch C, Shepard TF, Stampfer MJ et al. Amplified in breast cancer-1 glutamine repeat and prostate cancer risk. Prostate Journal 20002 27-32.

18 Hsing AW, Chokkalingam AP, Gao YT, Wu G, Wang X, Deng J et al. Polymorphic CAG/CAA repeat length in the AIB1/SRC-3 gene and prostate cancer risk: a population-based case-control study. Cancer Epidemiology Biomarkers and Prevention 200211 337-341.

19 Richards RI. Dynamic mutations: a decade of unstable expanded repeats in human genetic disease. Human Molecular Genetics 2001 $102187-2194$.

20 Hughes RE. Polyglutamine disease: acetyltransferases awry. Current Biology $200212141-143$.

Received 22 October 2002

Accepted 23 October 2002 